\title{
Sulodexide Protects Contrast-Induced Nephropathy in Sprague-Dawley Rats
}

\author{
Qing Zhao Jianyong Yin ${ }^{b}$ Zeyuan Lu ${ }^{b} \quad$ Yiwei Kong ${ }^{b} \quad$ Guangyuan Zhang ${ }^{b}$ \\ Binghui Zhaoc Feng Wang ${ }^{b}$ \\ aDepartment of Cardiology, Shanghai Jiao Tong University Affiliated Sixth People's Hospital; \\ ${ }^{b}$ Department of Nephrology, Shanghai Jiao Tong University Affiliated Sixth People's Hospital, Shanghai, \\ 'Department of Radiology, Shanghai Tenth People's Hospital Affiliated to Tongji University, Shanghai, \\ China
}

\section{Key Words}

Sulodexide $\bullet$ Contrast-induced nephropathy $\bullet$ Inflammation $•$ Oxidative stress $•$ Apoptosis

\begin{abstract}
Background: Sulodexide is a powerful antithrombin agent with reno-protective property. However, whether it has beneficial effects on Contrast-Induced Nephropathy (CIN) remained elusive. In the current study, we evaluated the therapeutic effects of Sulodexide on CIN and investigated the potential mechanisms. Methods: CIN model was induced by intravenous injection of indomethacin, followed by Ioversol and L-NAME. Sprague-Dawley rats were divided into 4 groups: control group, CIN group, CIN+vehicle group (CIN rats pretreated with vehicle) and CIN + Sulodexide (CIN rats pretreated with Sulodexide). Sulodexide or an equivalent volume of vehicle was intravenously delivered $30 \mathrm{~min}$ before the induction of CIN. All the animals were sacrificed at $24 \mathrm{~h}$ after CIN and tissues were harvested to evaluate renal injury, kidney oxidative stress and apoptosis levels. Plasma antithrombin III (ATIII) activities were also measured. Results: Compared to the untreated CIN group, improved renal function, reduced tubular injury, decreased levels of oxidative stress and apoptosis were observed in CIN rats receiving Sulodexide injection. In addition, we also found that ATIII activity was significantly higher in Sulodexide-administered group than that in vehicle-injected CIN rats. For in vitro studies, HK2 cells were exposed to Ioversol and the cyto-protective effects of Sulodexide were also determined. Sulodexide pretreatment protected HK2 cells against the cytotoxicity of Ioversol via inhibiting caspase-3 activity. Preincubation with Sulodexide could also attenuate $\mathrm{H}_{2} \mathrm{O}_{2}$-induced increases in ROS, apoptosis and caspase-3 levels. Conclusions: Taken together, Sulodexide could protect against CIN through activating ATIII, and inhibiting oxidative stress, inflammation and apoptosis.

Drs. Q. Zhao, J. Yin and Z. Lu contributed equally to this work.

Feng Wang, MD, Ph.D

Binghui Zhao, MD, Ph.D

KARGER
600 Yishan Road, Shanghai, 200233 (China)

301 Yanchangzhong Road, Shanghai 200072 (China)

E-Mail zyzwq1030@hotmail.com / drzhaobinghui@163.com 


\begin{tabular}{|c|c|}
\hline Cellular Physiology & Cell Physiol Biochem 2016;40:621-632 \\
\hline and Biochemistrv & \begin{tabular}{l|l}
\begin{tabular}{l|l} 
DOI: 10.1159/000452575 \\
Published online: November 30, 2016 The Author(s). Published by S. Karger AG, Basel \\
www.karger.com/cpp
\end{tabular}
\end{tabular} \\
\hline
\end{tabular}

\section{Introduction}

Contrast-induced nephropathy (CIN) has become the third leading cause of hospitalacquired acute kidney injury (AKI) due to massive use of radiocontrast media in diagnostic coronary angiography or percutaneous coronary intervention (PCI) procedures [1, 2]. CIN accounts for $10-25 \%$ in all cases of in-hospital AKI $[3,4]$, and is associated with increased morbidity, prolonged hospital stay and higher mortality [5-7]. However, there is still no effective prophylactic regimen available to prevent the occurrence of this life-threatening disease. Thus, it is urgent to uncover the pathogenesis of CIN and to identify novel preventive therapies to decrease CIN incidence and to improve clinical prognosis.

Although the exact pathophysiological mechanism of CIN still remains unknown, it has been generally demonstrated that CIN appears to be the result of combined effects of direct nephrotoxicity of contrast media and hypoxic renal injury $[8,9]$. Mounting evidence has shown that impaired renal blood flow and subsequent renal ischemia-reperfusion (I/R) injury plays a pivotal role in the pathogenesis of CIN $[10,11]$. In addition, inflammation, reactive oxygen species (ROS) formation and apoptosis also contribute to the renal tubular cell injury $[12,13]$. Recently, clinical studies reported that several potent free radicals scavenger, for example, $\mathrm{N}$-acetylcysteine can effectively reduce the incidence of CIN and improve outcomes $[14,15]$. Therefore, pharmacological agents with antioxidant and antiinflammation properties may be a promising preventive strategy for CIN.

Among various candidates that possess reno-protective effects, Sulodexide is a purified mixture of glycosaminoglycan composed of low molecular weight heparin and dermatan sulfate [16]. Sulodexide has anti-coagulant, anti-inflammatory [17, 18], and anti-oxidative effects [19], as well as the anti-ischemic effects [20]. It was reported that Sulodexide can improve endothelial dysfunction and reduce cell proliferation and matrix accumulation in the kidneys of diabetic rats [21]. Several clinical studies also showed that Sulodexide can reduce proteinuria in patients with diabetic nephropathy $[19,22,23]$. Given the properties of Sulodexide, it may be possible that Sulodexide administration can be a preventive treatment for CIN. In the present study, we hypothesized that Sulodexide might protect against CIN in rats. In vivo and in vitro CIN models were established and Sulodexide was administered to evaluate whether it has beneficial effects on CIN. Besides, the underlying mechanisms were also investigated.

\section{Materials and Methods}

\section{Regents}

Ioversol was purchased from Hengrui Corp. (Jiangsu, China). $N$-nitro- $L$-arginine methyl ester (L-NAME), indomethacin, and sodium taurocholate were obtained from Sigma-Aldrich (St Louis, Mo, USA). Sulodexide was purchased from Vessel Due F (Alfa Wassermann, Italy). The primary antibodies, rabbit anticaspase 3 and mouse anti-GAPDH were both purchased from Cell Signaling Technology (Danvers, MA, USA).

\section{Animal experimental protocols and rat CIN model}

Male Sprague-Dawley rats, weighing 250 \pm 20 g, were purchased from Shanghai Science Academy animal center. All the rats were housed under controlled light $(12 \mathrm{~h}$ dark $/ 12 \mathrm{~h}$ light cycle) and temperature $\left(20-23^{\circ} \mathrm{C}\right)$ conditions with free access to standard chow and water. This study was approved by the Animal Care and Ethics Committee of Shanghai Jiao Tong University Affiliated Sixth People's Hospital.

CIN model was established as we described previously [24, 25]. Briefly, rats were given a tail vein injection of indomethacin $(5 \mathrm{mg} / \mathrm{kg})$, followed by Ioversol $(3 \mathrm{~g} / \mathrm{kg}$ organically bound iodine) and L-NAME $(10 \mathrm{mg} / \mathrm{kg})$. Twenty-four rats were randomly divided into four groups ( $\mathrm{n}=6$ in each group): sham-operated group with injection of normal saline (CTL+ vehicle), CIN group with injection of normal saline (CIN + vehicle), and CIN group with pre-injection of Sulodexide (CIN+Sulodexide). Sulodexide (5mg/kg) or an equivalent volume of vehicle was intravenously delivered $30 \mathrm{~min}$ before CIN induction. The animals were sacrificed $24 \mathrm{~h}$ after induction of CIN. Blood and renal tissues were harvested for further analysis. The left 


\section{Cellular Physiology Cell Physiol Biochem 2016;40:621-632 \begin{tabular}{ll|l} 
DOI: 10.1159/000452575 & $\begin{array}{l}\text { O 2016 The Author(s). Published by S. Karger AG, Basel } \\
\text { www.karger.com/cpb }\end{array}$
\end{tabular} \\ Zhao et al.: Sulodexide and CIN}

kidney was harvested and the cortex was isolated for molecular analysis whereas the right kidney was fixed in $4 \%$ paraformaldehyde for histological assessments.

\section{Biochemical measurements}

Blood samples were collected from abdominal aorta and centrifuged to isolate serum, plasma, and then separated into aliquots and stored at $-80^{\circ} \mathrm{C}$ until analyzed. Blood urea nitrogen (BUN) and serum creatinine (Scr) were measured by an automatic biochemical analyzer 7600 (Hitachi, Tokyo, Japan) to evaluate the alteration of renal function. Plasma ATIII activities measurement was performed using an automatic coagulation analysis machine (Sysmex CA7000, SIEMENS, Munich, Germany).

\section{Measurement of oxidative stress markers}

The levels of MDA and SOD in renal tissue homogenate were measured using commercial kits according to the manufacturer's protocol (Beyotime, Jiangsu, China). Both the final concentrations of MDA and SOD were normalized to the protein concentration of tissue homogenate.

\section{Histological injury assessment}

The paraformaldehyde-fixed kidney was embedded in paraffin and then was cut into $3 \mu \mathrm{m}$ sections. Histological injuries were evaluated by Periodic acid-Schiff (PAS) staining. To quantify the renal injury, we used a scoring system grading tubular necrosis, tubular dilatation, loss of brush border, and cast formation in 10 randomly chosen, non-overlapping fields as described previously [25]. The severity of renal injury was semiquantified by the following criteria: 0 , none; $1,0-10 \% ; 2,11-25 \% ; 3,26-45 \% ; 4,46-75 \%$; and $5,76-$ $100 \%[26]$. All evaluation was performed by an observer who was blind to the study groups.

\section{TUNEL Staining}

Apoptosis of tubular cells in the kidney was examined by terminal transferase-mediated dUTP nickend labeling (TUNEL) staining with a rat In Situ Cell Death Detection Kit (Roche, Mannheim, Germany) on paraffin-embedded sections as previously described. Briefly, kidney sections were deparaffinized, rehydrated, and digested with protein $\mathrm{K}$ and incubated with TUNEL reaction mixture for $60 \mathrm{~min}$ at $37^{\circ} \mathrm{C}$. Sections were examined by fluorescence microscopy, and 10 random sections were counted for every kidney under $\times 400$ magnification.

\section{Macrophage infiltration in renal tissues}

Kidney paraffin sections were stained with anti-rat monoclonal antibodies against CD68 (Abcam, Cambridge, MA, USA) to identify infiltrated macrophages in renal tissue as previously described [27].

An oxidative stress model of HK2 cells

Human proximal tubular epithelial cells (HK2 cells) from ATCC (Rockefeller, MD, USA) were cultured in DMEM/F12 at $37^{\circ} \mathrm{C} 5 \% \mathrm{CO}$, supplemented with $5 \mathrm{ng} / \mathrm{ml}$ human recombinant EGF and $0.05 \mathrm{mg} / \mathrm{ml}$ bovine pituitary extract. To investigate whether Sulodexide could protect against induced $\mathrm{H}_{2} \mathrm{O}_{2}$ oxidative injury, HK2 cells were preincubated with vehicle or Sulodexide $(10,50 \mu \mathrm{g} / \mathrm{ml}) 1$ hour. Then HK2 cells were exposed to $\mathrm{H}_{2} \mathrm{O}_{2}(500 \mu \mathrm{mol} / \mathrm{L})$ for an additional $12 \mathrm{~h}$. The released lactate dehydrogenase (LDH) levels in the supernatant were measured by a commercial assay kit (Beyotime, China). Cell apoptosis was measured with a Cell Death Detection ELISA kit (\#11544675001, Roche) and intracellular reactive oxygen species (ROS) (Cell Biolabs, USA).

\section{Quantitative real-time PCR}

Total RNA from HK2 cells or kidney tissues was isolated using Trizol (Invitrogen, Carlsbad, CA, USA) and was reverse transcribed with M-MLV Reverse Transcriptase (Promega, Madison, WI, USA). Real-time PCR was performed with SYBE Green PCR master Mix (Tarkara, Dalian, China) using StepOnePlus PCR Systems (Applied Biosystems, Foster City, CA, USA) as previously described [25]. Primer pairs were as following: rat TNF $\alpha$ : 5'GTCTGTGCCTCAGCCTCTTC3' (forward) and 5'TGGAACTGATGAGAGGGAGC3' (reverse); rat MCP-1: 5'CCCСACTCACCTGCTGCTAC3' (forward) and 5'CCTGCTGCTGGTGATTCTCTT3' (reverse). Quantitation was normalized to internal control $18 \mathrm{~S}$ rRNA and $2^{-\Delta \Delta C \mathrm{~T}}$ method was used to determine relative gene expression levels. 


\section{Cellular Physiology Cell Physiol Biochem 2016;40:621-632

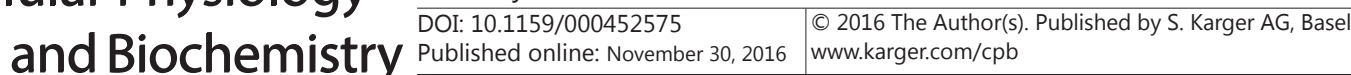 \\ Zhao et al.: Sulodexide and CIN}

Western blot analysis

Total protein was prepared from frozen tissues by homogenization. Protein concentrations were determined by BCA assay (Beyotime, Suzhou, Jiangsu, China) and protein samples were separated by $10 \%$ to $12 \%$ sodium dodecyl sulfate-polyacrylamide gels. Proteins were then transferred to polyvinylidene difluoride membrane and blocked with 5\% non-fat dried milk. The membranes were then incubated with primary antibody overnight at $4{ }^{\circ} \mathrm{C}$ and with HRP-conjugated secondary antibodies (Beyotime) for 2 hours at room temperature. The blotting signals were imaged using the Image Quant LAS 4000 Mini System (GE Healthcare, Pittsburgh, PA, USA). The bands were analyzed using Image J software and GAPDH or tubulin was used as internal control.

\section{Statistical analysis}

The software of GraphPad Prism was used for data analysis. All the data were expressed as mean \pm standard error. One-way ANOVA with Sidak compensation followed by a Tukey's Multiple Comparison Test was used to compare the differences in groups. A value of $P<0.05$ was considered statistically significant.

\section{Results}

Sulodexide decreased serum levels of Scr and BUN in CIN rats

As shown in Fig. 1A-B, rats in CIN groups displayed significant deterioration of renal function $24 \mathrm{~h}$ after administration of contrast media, as reflected by remarkably increased levels of Scr and BUN compared with that in sham rats. However, the elevation of Scr and BUN was significantly blunted in CIN rats pre-treated with Sulodexide (Scr, CIN+Sulodexide vs. CIN+veh, $P<0.05$; BUN, $\mathrm{CIN}+$ Sulodexide vs. $\mathrm{CIN}+\mathrm{veh}, P<0.05)$. These results suggested that Sulodexide was able to protect against Ioversol-induced kidney injury.

Sulodexide increased plasma ATIII activity in CIN rats.

As revealed in Fig. 1C, contrast infusion led to significant decrease in plasma ATIII activity $(P<0.05)$. However, Sulodexide pretreatment resulted in modest but significant elevation in plasma ATIII activity in comparison with un-treated CIN groups.

\section{Sulodexide administration attenuated renal pathological injury}

Kidney sections stained with PAS from CIN and CIN+Veh groups revealed that Ioversol injection resulted in a typical tubular injury characterized by pronounced degeneration of tubular architecture, renal tubular detachment, tubular cell necrosis, intratubular cast formation and luminal congestion with loss of brush border. And these histological changes in Sulodexide pre-treatment group were less severe than that in CIN and CIN+Veh groups
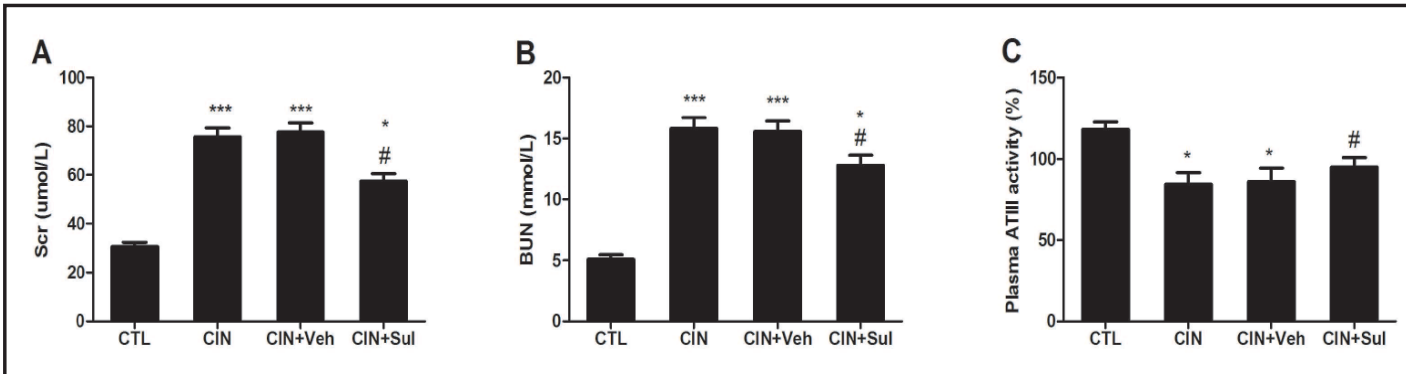

Fig. 1. Effects of Sulodexide on alteration of biochemistry parameters. Contrast-induced nephropathy (CIN) was induced in rats and blood was obtained for further analysis at $24 \mathrm{~h}$ after CIN. A. Blood urea nitrogen. B. Serum creatinine. C. Plasma ATIII activity. CTL, normal-controlled group; CIN, contrast induced nephropathy group; CIN+Veh, contrast induced nephropathy group with vehicle injection; CIN+Sul, contrast induced nephropathy group with Sulodexide injection. Data were presented as means \pm SEM $(n=6) .{ }^{*} P<0.05$ versus CTL, ${ }^{* * *} P<0.001$ versus CTL; ${ }^{\#} P<0.05$ versus $\mathrm{CIN}+$ Veh. 
A

CTL

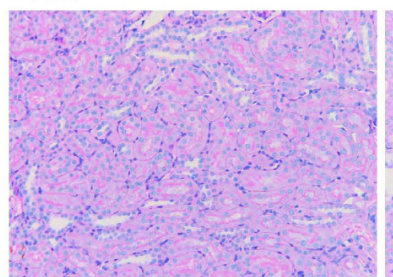

CIN+Veh
CIN

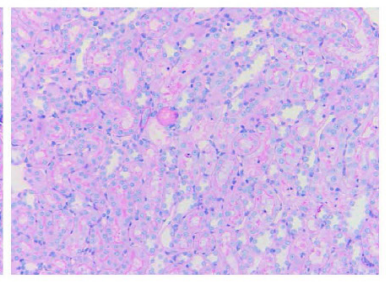

CIN+Sul

B

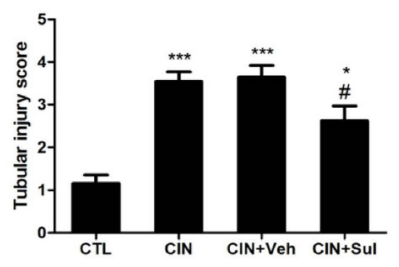

Fig. 2. Sulodexide administration attenuated renal pathological injury after contrast infusion. Kidney sections were stained with periodic acid-Schiff (PAS) and a semi-quantitative scoring system was utilized to assess the extent of tubular injury. A. Representative pictures of renal PAS staining (magnification, 400×). B. Semi-quantitative analysis of tubular injury score. Data were presented as means \pm SEM $(n=6) .{ }^{~} P<0.05$ versus CTL, " ${ }^{* *} P<0.001$ versus CTL; ${ }^{\#} P<0.05$ versus $\mathrm{CIN}+$ Veh.

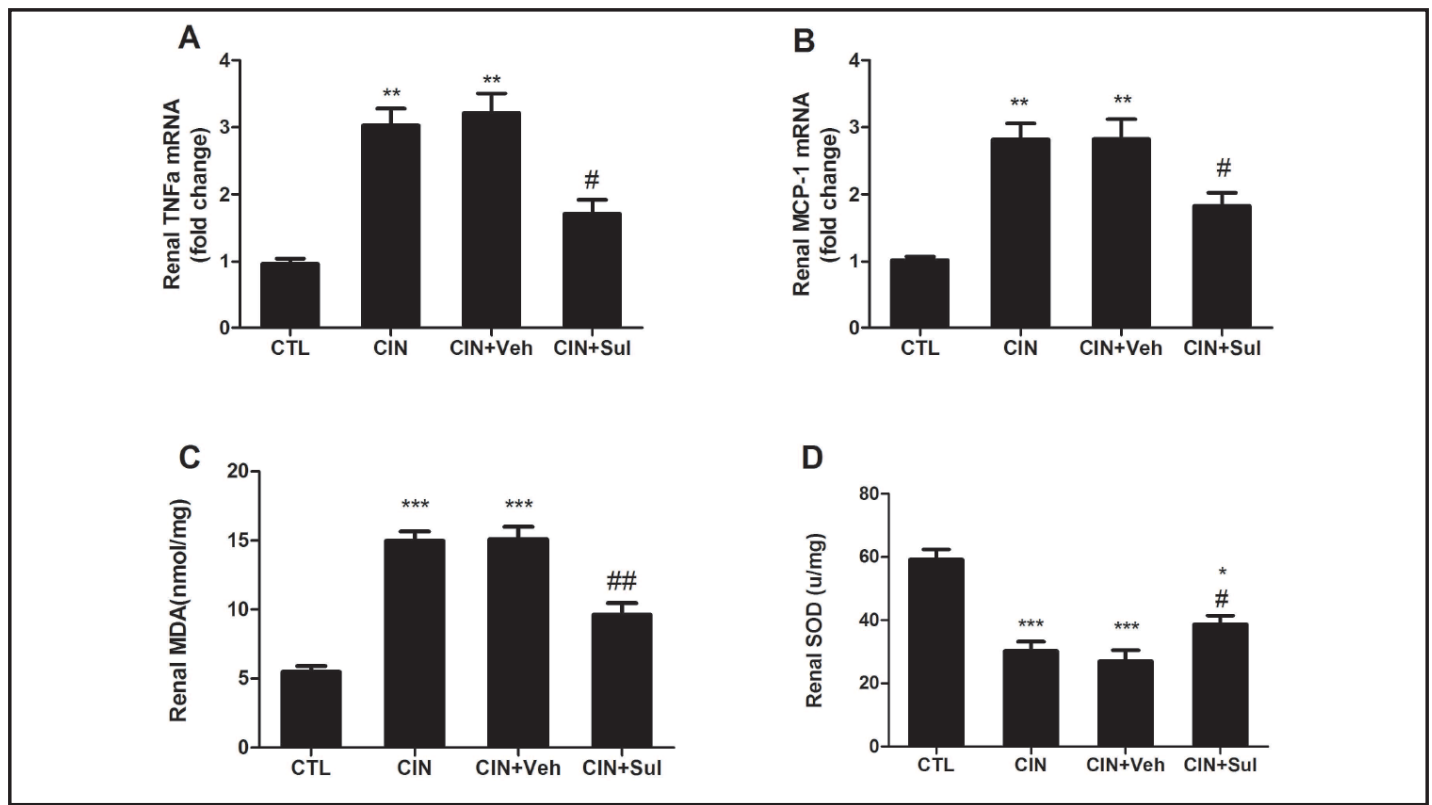

Fig. 3. Effects of Sulodexide on renal inflammation and oxidative stress. The levels of malondialdehyde (MDA) and superoxide dismutase (SOD) were measured to determine the alteration of oxidative stress. Expression of pro-inflammatory cytokines in kidney tissue was detected by real-time PCR. A. Renal TNF $\alpha$ mRNA expression. B. Renal MCP-1 mRNA expression. C. Renal MDA. D. Renal SOD. Data were presented as means \pm SEM $(\mathrm{n}=6)$. ${ }^{*} P<0.05$ versus $\mathrm{CTL},{ }^{* *} P<0.01$ versus $\mathrm{CTL},{ }^{* * *} P<0.001$ versus $\mathrm{CTL}$; ${ }^{\#} P<0.05$ versus $\mathrm{CIN}+\mathrm{Veh},{ }^{\# \#} P<0.01$ versus $\mathrm{CIN}+\mathrm{Veh}$.

(Fig. 2A). Consistently with the alterations of biochemical parameters and PAS staining, semiquantitative assessment of the histological lesions exhibited a significantly lower score in the Sulodexide-treated rats compared with the un-treated groups at $24 \mathrm{~h}$ after CIN induction. 


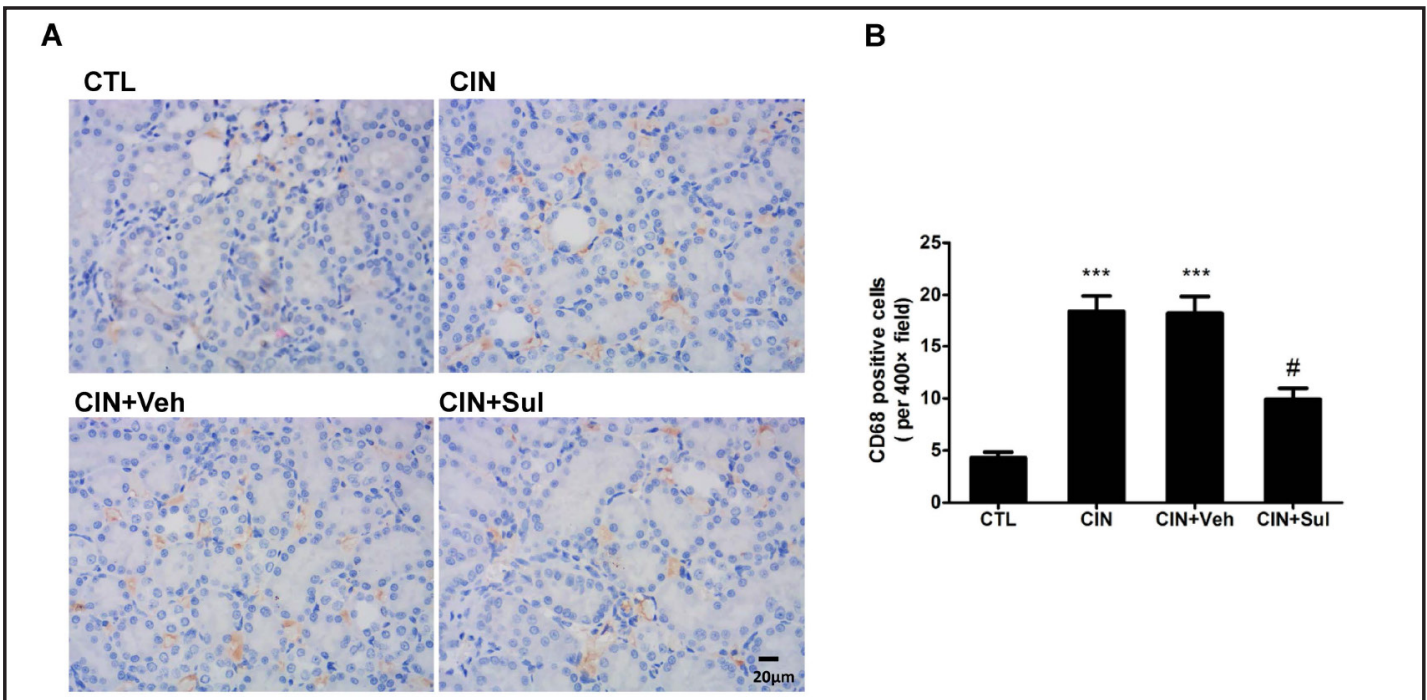

Fig. 4. Sulodexide reduced renal macrophage infiltration in CIN rats. Paraffin sections were stained with rabbit anti-CD68 antibody to examine the effects of Sulodexide on macrophage infiltration after contrast infusion. A. Representative picture of immuno-stained sections (magnification, $\times 400$ ). B. quantitative analysis of CD68-positive cells per field. Data were presented as means \pm SEM $(\mathrm{n}=6)$. ${ }^{* * *} P<0.001$ versus CTL; ${ }^{\#} P<0.05$ versus CIN+Veh.

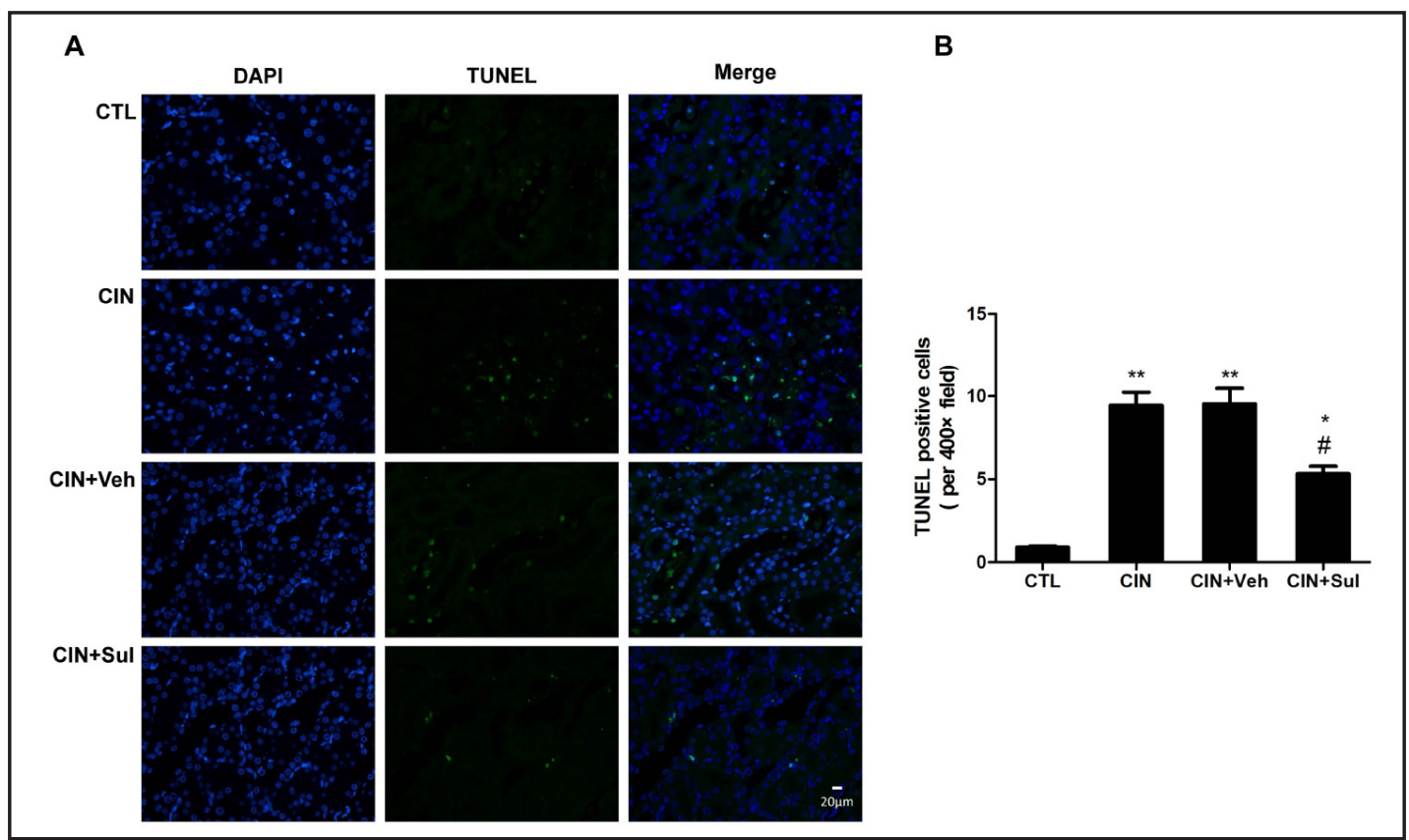

Fig. 5. Renal apoptosis was alleviated in Sulodexide-treated CIN rats. Terminal deoxynucleotidyl transferase dUTP nick end labeling (TUNEL) staining was used to evaluate tubular cell apoptosis. A. Representative pictures of TUNEL staining (magnification, $\times 400$ ). B. Semi-quantitative analysis of the number of apoptotic cells per field. Data were presented as means \pm SEM $(n=6) .{ }^{*} P<0.05$ versus $C T L,{ }^{* *} P<0.01$ versus CTL; ${ }^{\#} P<0.05$ versus CIN+Veh.

Sulodexide inhibited renal inflammation and oxidative stress in CIN rats

To explore the reno-protective mechanisms of Sulodexide in CIN, the effects of Sulodexide on inflammation and oxidative stress levels were examined. As shown in Fig. $3 \mathrm{~A}-\mathrm{B}$, the renal mRNA expression levels of tumor necrosis factor $\alpha$ (TNF $\alpha$ ) and monocyte chemotactic protein 1 (MCP-1) in CIN rats were substantially increased compared with 
A

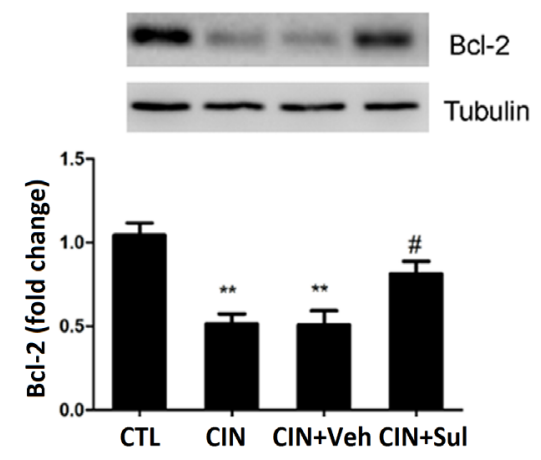

C

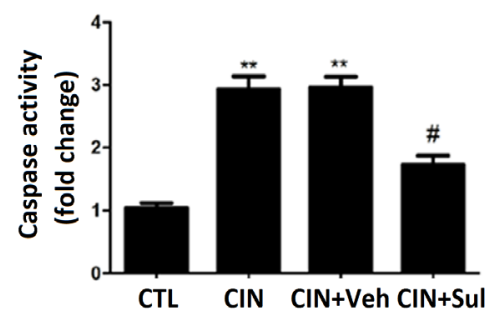

B

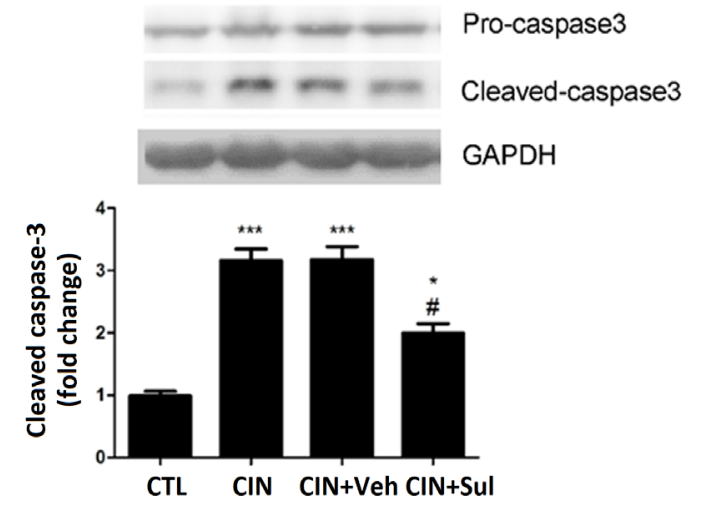

Fig. 6. Effects of Sulodexide administration on caspase3 activity and cleavage in CIN rats. Kidney tissues were harvested $24 \mathrm{~h}$ after contrast infusion. Caspase 3 activity and cleaved-caspases expression in tissue homogenate were measured. A. Renal caspase 3 protein expression. B. Changes of caspase 3 activity. Data were

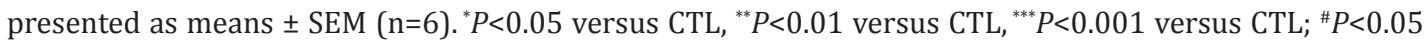
versus CIN+Veh.

sham rats, and Sulodexide administration inhibited TNF $\alpha$ and MCP-1 expression in CIN rats. Furthermore, immunostaining analysis showed that CIN led to increased CD68-positive macrophage infiltration in kidney, which was mitigated by Sulodexide pre-treatment (Fig. 4). In addition, we also found that renal malondialdehyde (MDA) levels were increased in CIN rats whereas superoxide dismutase (SOD) activity was decreased in CIN rats compared with the normal control group (Fig. 3C-D). Pretreatment with Sulodexide reduced renal MDA levels and restored renal SOD levels, indicating that Sulodexide could ameliorate oxidative stress from both directions in rats with CIN. Taken together, Sulodexide might exert its renoprotective effects against CIN through inhibiting inflammatory response and oxidative stress.

\section{Sulodexide mitigated renal apoptosis caused by contrast injection}

To explore whether Sulodexide's beneficial effects on CIN were associated with apoptosis changes, we performed terminal deoxynucleotidyl transferase-mediated digoxigenindeoxyuridine nick-end labeling (TUNEL) staining on the kidney sections from rats with CIN or sham-operated group. In comparison to normal control rats, contrast injection led to elevated apoptosis, and Sulodexide could dramatically inhibit contrast induced apoptosis in kidney (Fig. 5). Moreover, the expression of caspase-3 and bcl-2 was analyzed. Similar to TUNEL assay, western blot analysis suggested that CIN led to substantial increase in cleaved caspases-3 expression and decrease in anti-apoptotic proteins bcl-2 expression as indicated in Fig. 6. Our data proved that caspases-3 activation was effectively repressed while bcl-2 expression was restored nearly to control levels by Sulodexide preconditioning. In summary, Sulodexide administration mitigated renal tubular cell apoptosis following CIN. 


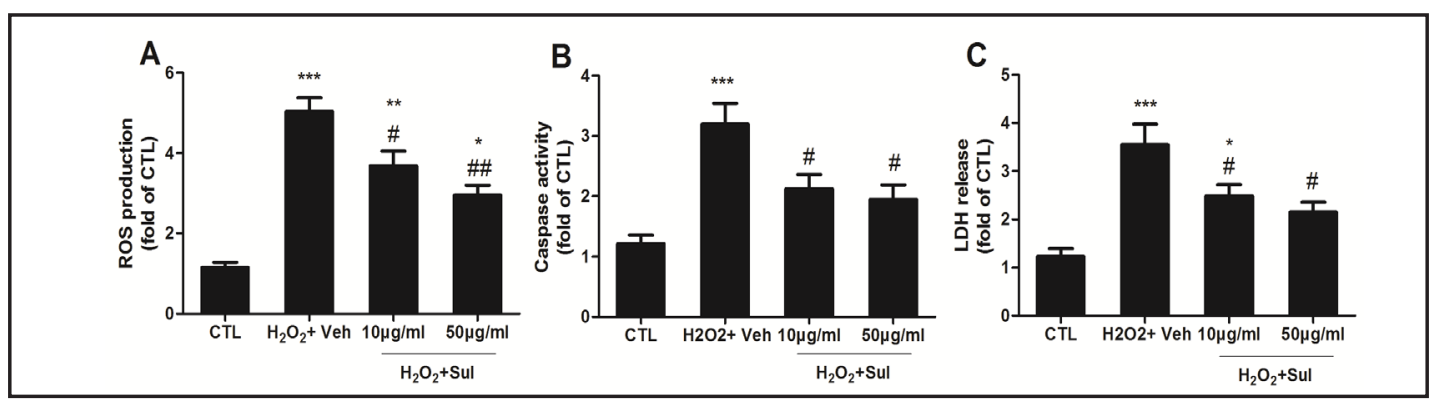

Fig. 7. Sulodexide pretreatment protected against Ioversol's cytotoxicity in HK-2 cells. HK2 cells were cultured to subconfluence, and then starved in serum-free medium for 24 hours with Sulodexide $(10,50 \mu \mathrm{g} /$ $\mathrm{ml}) 1$ hour prior to exposure to $\mathrm{H}_{2} \mathrm{O}_{2}(500 \mu \mathrm{mol} / \mathrm{L})$ for additional 8 hours. Data were presented as means \pm SEM and were representative of three independent experiments. ${ }^{*} P<0.05$ versus CTL, ${ }^{* *} P<0.01$ versus CTL, ${ }^{* * *} P<0.001$ versus CTL; ${ }^{\#} P<0.05$ versus $\mathrm{H}_{2} \mathrm{O}_{2}+$ Veh, ${ }^{\# \#} P<0.01$ versus $\mathrm{H}_{2} \mathrm{O}_{2}+$ Veh.

\section{Sulodexide protected against H2O2's cytotoxicity, oxidative stress and prevented apoptosis} in vitro

To validate whether Sulodexide possesses cyto-protecive properties in vitro, hydrogen peroxide was used to induce oxidative cell injuries in HK-2 cells. As shown in Fig. 7, $\mathrm{H}_{2} \mathrm{O}_{2}$ cause a remarkable elevation in LDH release and apoptosis when compared with controls. In contrast, preincubation with Sulodexide for $1 \mathrm{~h}$ significantly protected against $\mathrm{H}_{2} \mathrm{O}_{2}$ mediated cell death in a dose-dependent manner. $\mathrm{H}_{2} \mathrm{O}_{2}$-induced increases in ROS, apoptosis and caspase-3 levels were also suppressed by Sulodexide pretreatment. These data indicated that Sulodexide could exert its cyto-protective effect directly via inhibiting apoptosis and attenuating oxidative stress.

\section{Discussion}

CIN is a complex complication with a high incidence in clinical diagnostic and interventional procedures. Moreover, the incidence of CIN is relatively high in patients with mild to moderate chronic renal insufficiency, old age and diabetes and can reach up to $50 \%$ in patients underwent PCI [28]. Due to its high morbidity and mortality rates, CIN has become a growing concern in clinical practice. Although numerous efforts have been made to find a preventive strategy to decrease CIN incidence and some antioxidants appear to be effective $[29,30]$, the consensus is still out due to inconsistent results amongst the literature [31]. Thus, it is of great clinical value to develop new therapeutic interventions for CIN.

The present study demonstrated that Sulodexide pre-administration could protect against AKI after contrast infusion. Our data indicated that Sulodexide ameliorated deterioration of renal function and histopathological kidney injury in CIN rats, which was accompanied with increased plasma ATIII activity, reduced oxidative stress, macrophage infiltration and apoptosis. Additionally, Sulodexide pretreatment inhibited $\mathrm{H}_{2} \mathrm{O}_{2}$-induced ROS production, LDH release and activation of caspases 3 in vitro. These data suggest that Sulodexide may mediate its reno-protective effects through anti-oxidation, anti-inflammation and anti-apoptosis mechanisms.

Currently, although the exact pathophysiology of CIN is not yet fully elucidated, the pathogenesis of CIN is primarily due to continued renal hypoperfusion in the renal medulla [11]. It has been reported that contrast media can result in hemodynamic alteration of renal blood flow such as vasoconstriction, and led to subsequent renal I/R injury. In this study, we found that Ioversol infusion induced decrease in plasma ATIII activity while Sulodexide pretreatment significantly restored ATIII activity, which was consistent with Sulodexide's biological properties of promoting activation of ATIII [32, 33]. Our previous studies demonstrated that low ATIII activity increased the susceptibility to AKI after cardiac surgery in patients and endogenous ATIII insufficiency and exacerbated renal I/R injury in animal 


\section{Cellular Physiology Cell Physiol Biochem 2016;40:621-632 \\ \begin{tabular}{ll|l} 
and Biochemistry 1159/000452575 & $\begin{array}{l}\text { O 2016 The Author(s). Published by S. Karger AG, Basel } \\
\text { Published online: November 30, } 2016\end{array}$ \\
\cline { 2 - 3 } ww.karger.com/cpb
\end{tabular} \\ Zhao et al.: Sulodexide and CIN}

model [34]. We found that ATIII could promote the release of prostaglandin $\mathrm{I}_{2}\left(\mathrm{PGI}_{2}\right)$, which is a powerful vasodilator [35]. These data indicated that Sulodexide might mediate its renoprotection via its antithrombotic activity by activating ATIII and ultimately restore the renal blood flow.

The generation of excessive levels of ROS under hypoxia can directly cause tubular damage, endothelial dysfunction, and dysfunction of tubular transport, thus, oxidative stress also play a pivotal role in the development of CIN [36,37]. Reactive species imbalance causes lipid peroxidation, thereby leading to cytotoxic damage. Lipid peroxidation is generally measured on the basis of the production of MDA, which is an indicator of oxidative damage. In agreement with previous studies [36, 38, 39], we observed remarkable increase in renal MDA and decrease in renal SOD in CIN rats, which indicated the presence of oxidative damage. However, Sulodexide-preconditioned rats exhibited lower renal MDA and higher renal SOD levels. Besides, pretreatment with Sulodexide directly repressed $\mathrm{H}_{2} \mathrm{O}_{2}$ induced ROS generation in HK2 cells. Consistently with our data, the antioxidant effects of Sulodexide have also been reported in previous studies [19]. We believed that the reno-protective effect of Sulodexide can be attributed to the direct inhibition of ROS production.

Apoptosis also contributed to the occurrence of CIN. Cumulative evidence has suggested that contrast agent leads to renal tubular cell apoptosis through the ROS pathway, the stress kinase pathway and the intrinsic apoptotic pathway [40,41]. Our study proved that caspase 3 activation, in other words, the intrinsic apoptotic pathway was involved in the contrast induced renal injury, which was reported in our recent studies $[24,25,39]$ and other reports [38]. Sulodexide might exert its inhibitory effect on apoptosis via a direct inhibition of caspases, which was evidenced that Sulodexide increased the viability of $\mathrm{H}_{2} \mathrm{O}_{2}$-injured $\mathrm{HK} 2$ cells in vitro, or in an indirect manner by its ability of ROS clearance.

Previous studies have demonstrated that Sulodexide possesses anti-inflammatory properties [18, 42, 43]. We also found that Sulodexide decreased pro-inflammatory cytokines and macrophage infiltration. Besides, it has been suggested that Sulodexide can maintain or restore endothelial cells function $[44,45]$, whether Sulodexide has beneficial effects on endothelial cells in CIN and other molecular mechanisms remain to be determined in the future. As a common AKI, CIN not only can result in longer in-hospital stay and higher rates of in-hospital complications and 1-year mortality, but also can lead to AKI-chronic kidney disease transition, another big clinical problem [46, 47]. In a word, CIN is still a big challenge in the clinical practice [48-51]. However, this work brings some new insights into the biological effects of Sulodexide in CIN.

\section{Conclusion}

Our data suggested that Sulodexide attenuated renal injury in CIN model and these beneficial effects are mainly mediated via anti-coagulation, anti-oxidation and anti-apoptotic effects. Thus, Sulodexide may represent a potential drug for prevention of CIN; nevertheless, further studies are required to determine its reno-protective effects in the future.

\section{Acknowledgements}

This work was sponsored by the National Natural Science Foundation of China (81570603), the New-100 talent Plan of Shanghai Jiao Tong University School of Medicine (2012), the medical guide project of the science and technology commission of Shanghai (16411969100), Shanghai Talents Development Fundation (201350) and Shanghai Pujiang Talent Projects (15PJ1406700). Thanks to Dr. Maokang Wang for language editing.

\section{Disclosure Statement}

The authors declare that there is no conflict of interests regarding the publication of this paper. 


\section{Cellular Physiology Cell Physiol Biochem 2016;40:621-632 and Biochemistry Published online: November 30, 2016 \begin{tabular}{l|l} 
DOI: 10.1159/000452575 2016 The Author(s). Published by S. Karger AG, Basel \\
www.karger.com/cpb
\end{tabular} \\ Zhao et al.: Sulodexide and CIN}

\section{References}

1 Nash K, Hafeez A, Hou S: Hospital-acquired renal insufficiency. Am J Kidney Dis 2002;39:930-936.

2 Hou SH, Bushinsky DA, Wish JB, Cohen JJ, Harrington JT: Hospital-acquired renal insufficiency: A prospective study. Am J Med 1983;74:243-248.

3 Feldkamp T, Kribben A: Contrast media induced nephropathy: Definition, incidence, outcome, pathophysiology, risk factors and prevention. Minerva Med 2008;99:177-196.

4 Gleeson TG, Bulugahapitiya S: Contrast-induced nephropathy. Am J Roentgenol 2004;183:1673-1689.

5 Finn WF: The clinical and renal consequences of contrast-induced nephropathy. Nephrol Dial Transplant 2006;21:i2-10.

6 Wang F, Peng C, Zhang G, Zhao Q, Xuan C, Wei M, Wang N: Delayed kidney injury following coronary angiography. Exp Ther Med 2016;12:530-534.

7 Maioli M, Toso A, Leoncini M, Gallopin M, Musilli N, Bellandi F: Persistent renal damage after contrastinduced acute kidney injury: Incidence, evolution, risk factors, and prognosis. Circulation 2012;125:30993107.

8 Persson PB, Tepel M: Contrast medium-induced nephropathy: The pathophysiology. Kidney Int 2006:S8-10.

9 Persson PB, Hansell P, Liss P: Pathophysiology of contrast medium-induced nephropathy. Kidney Int Suppl 2005;68:14-22.

10 Evans RG, Ince C, Joles JA, Smith DW, May CN, O'Connor PM, Gardiner BS: Haemodynamic influences on kidney oxygenation: Clinical implications of integrative physiology. Clin Exp Pharmacol Physiol 2013;40:106-122.

11 Seeliger E, Flemming B, Wronski T, Ladwig M, Arakelyan K, Godes M, Mockel M, Persson PB: Viscosity of contrast media perturbs renal hemodynamics. J Am Soc Nephrol 2007;18:2912-2920.

12 Heyman SN, Rosen S, Khamaisi M, Idee JM, Rosenberger C: Reactive oxygen species and the pathogenesis of radiocontrast-induced nephropathy. Invest Radiol 2010;45:188-195.

13 Pisani A, Riccio E, Andreucci M, Faga T, Ashour M, Di Nuzzi A, Mancini A, Sabbatini M: Role of reactive oxygen species in pathogenesis of radiocontrast-induced nephropathy. Biomed Res Int 2013:868321.

14 Wang N, Qian P, Kumar S, Yan TD, Phan K: The effect of n-acetylcysteine on the incidence of contrastinduced kidney injury: A systematic review and trial sequential analysis. Int J Cardiol 2016;209:319-327.

15 Marenzi G, Assanelli E, Marana I, Lauri G, Campodonico J, Grazi M, De Metrio M, Galli S, Fabbiocchi F, Montorsi P, Veglia F, Bartorelli AL: N-acetylcysteine and contrast-induced nephropathy in primary angioplasty. N Engl J Med 2006;354:2773-2782.

16 Ofosu FA: Pharmacological actions of Sulodexide. Semin Thromb Hemost 1998;24:127-138.

17 Karon J, Polubinska A, Antoniewicz AA, Suminska-Jasinska K, Breborowicz A: Anti-inflammatory effect of Sulodexide during acute peritonitis in rats. Blood Purif 2007;25:510-514.

18 Mannello F, Ligi D, Canale M, Raffetto JD: Sulodexide down-regulates the release of cytokines, chemokines, and leukocyte colony stimulating factors from human macrophages: Role of glycosaminoglycans in inflammatory pathways of chronic venous disease. Curr Vasc Pharmacol 2014;12:173-185.

19 Shu J, Zeng LY, Lin KY, Mu PW, Zhang GC, Chen YM, Wang MM: Renal protective effects of Sulodexide in diabetic rats and its anti-oxidative mechanism. Nan Fang Yi Ke Da Xue Xue Bao 2009;29:778-780.

20 Lauver DA, Booth EA, White AJ, Poradosu E, Lucchesi BR: Sulodexide attenuates myocardial ischemia/ reperfusion injury and the deposition of c-reactive protein in areas of infarction without affecting hemostasis. J Pharmacol Exp Ther 2005;312:794-800.

21 Ceol M, Gambaro G, Sauer U, Baggio B, Anglani F, Forino M, Facchin S, Bordin L, Weigert C, Nerlich A, Schleicher ED: Glycosaminoglycan therapy prevents tgf-beta1 overexpression and pathologic changes in renal tissue of long-term diabetic rats. J Am Soc Nephrol 2000;11:2324-2336.

22 Masola V, Zaza G, Gambaro G: Sulodexide and glycosaminoglycans in the progression of renal disease. Nephrol Dial Transplant 2014;29:i74-i79.

23 Lewis EJ, Lewis JB, Greene T, Hunsicker LG, Berl T, Pohl MA, de Zeeuw D, Heerspink HL, Rohde RD, Atkins RC, Reutens AT, Packham DK, Raz I, Collaborative Study G: Sulodexide for kidney protection in type 2 diabetes patients with microalbuminuria: A randomized controlled trial. Am J Kidney Dis 2011;58:729736.

24 Wang F, Yin J, Lu Z, Zhang G, Li J, Xing T, Zhuang S, Wang N: Limb ischemic preconditioning protects against contrast-induced nephropathy via renalase. EBioMedicine 2016;9:356-365. 


\section{Cellular Physiology Cell Physiol Biochem 2016;40:621-632 \begin{tabular}{l|l|l} 
and Biochemistry 10.1159/000452575 & $\begin{array}{l}\text { ( ) 2016 The Author(s). Published by S. Karger AG, Basel } \\
\text { www.karger.com/cpb }\end{array}$
\end{tabular} \\ Zhao et al.: Sulodexide and CIN}

25 Zhao B, Zhao Q, Li J, Xing T, Wang F, Wang N: Renalase protects against contrast-induced nephropathy in sprague-dawley rats. PloS one 2015;10:e0116583.

26 Melnikov VY, Faubel S, Siegmund B, Lucia MS, Ljubanovic D, Edelstein CL: Neutrophil-independent mechanisms of caspase-1- and il-18-mediated ischemic acute tubular necrosis in mice. J Clin Invest 2002;110:1083-1091.

27 Yin J, Lu Z, Wang F, Jiang Z, Lu L, Miao N, Wang N: Renalase attenuates hypertension, renal injury and cardiac remodelling in rats with subtotal nephrectomy. J Cell Mol Med 2016;20:1106-1117.

28 Marenzi G, Lauri G, Assanelli E, Campodonico J, De Metrio M, Marana I, Grazi M, Veglia F, Bartorelli AL: Contrast-induced nephropathy in patients undergoing primary angioplasty for acute myocardial infarction. J Am Coll Cardiol 2004;44:1780-1785.

29 Windecker S, Kolh P, Alfonso F, Collet JP, Cremer J, Falk V, Filippatos G, Hamm C, Head SJ, Juni P, Kappetein AP, Kastrati A, Knuuti J, Landmesser U, Laufer G, Neumann FJ, Richter DJ, Schauerte P, Sousa Uva M, Stefanini GG, Taggart DP, Torracca L, Valgimigli M, Wijns W, Witkowski A: 2014 esc/eacts guidelines on myocardial revascularization: The task force on myocardial revascularization of the european society of cardiology (esc) and the european association for cardio-thoracic surgery (eacts)developed with the special contribution of the european association of percutaneous cardiovascular interventions (eapci). Eur Heart J 2014;35:2541-2619.

30 Efrati S, Berman S, Ilgiyeav I, Siman-Tov Y, Averbukh Z, Weissgarten J: Differential effects of $\mathrm{n}$-acetylcysteine, theophylline or bicarbonate on contrast-induced rat renal vasoconstriction. Am J Nephrol 2009;29:181-191.

31 Rear R, Bell RM, Hausenloy DJ: Contrast-induced nephropathy following angiography and cardiac interventions. Heart 2016;102:638-648.

32 Buchanan MR, Liao P, Smith LJ, Ofosu FA: Prevention of thrombus formation and growth by antithrombin iii and heparin cofactor ii-dependent thrombin inhibitors: Importance of heparin cofactor ii. Thromb Res 1994;74:463-475.

33 Radhakrishnamurthy B, Sharma C, Bhandaru RR, Berenson GS, Stanzani L, Mastacchi R: Studies of chemical and biologic properties of a fraction of Sulodexide, a heparin-like glycosaminoglycan. Atherosclerosis 1986;60:141-149.

34 Wang F, Zhang G, Lu Z, Geurts AM, Usa K, Jacob HJ, Cowley AW, Wang N, Liang M: Antithrombin III/serpinc1 insufficiency exacerbates renal ischemia/reperfusion injury. Kidney Int 2015;88:796-803.

35 Johannes T, Ince C, Klingel K, Unertl KE, Mik EG: Iloprost preserves renal oxygenation and restores kidney function in endotoxemia-related acute renal failure in the rat. Crit Care Med 2009;37:1423-1432.

36 Zager RA, Johnson AC, Hanson SY: Radiographic contrast media-induced tubular injury: Evaluation of oxidant stress and plasma membrane integrity. Kidney Int 2003;64:128-139.

37 Zhao Z, Liao G, Zhou Q, Lv D, Holthfer H, Zou H: Sulforaphane attenuates contrast-induced nephropathy in rats via nrf2/ho-1 pathway. Oxid Med Cell Longev 2016;2016:9825623.

38 He X, Li L, Tan H, Chen J, Zhou Y: Atorvastatin attenuates contrast-induced nephropathy by modulating inflammatory responses through the regulation of jnk/p38/hsp27 expression. J Pharmacol Sci 2016;131:18-27.

39 Wang F, Zhang G, Zhou Y, Gui D, Li J, Xing T, Wang N: Magnolin protects against contrast-induced nephropathy in rats via antioxidation and antiapoptosis. Oxid Med Cell Longev 2014;2014:203458.

40 Quintavalle C, Brenca M, De Micco F, Fiore D, Romano S, Romano MF, Apone F, Bianco A, Zabatta MA, Troncone G, Briguori C, Condorelli G: In vivo and in vitro assessment of pathways involved in contrast media-induced renal cells apoptosis. Cell Death Dis 2011;2:e155.

41 Rudnick MR, Goldfarb S, Wexler L, Ludbrook PA, Murphy MJ, Halpern EF, Hill JA, Winniford M, Cohen MB, VanFossen DB: Nephrotoxicity of ionic and nonionic contrast media in 1196 patients: A randomized trial. The iohexol cooperative study. Kidney Int 1995;47:254-261.

42 Urbanek T, Zbigniew K, Begier-Krasinska B, Baum E, Breborowicz A: Sulodexide suppresses inflammation in patients with chronic venous insufficiency. Int Angiol 2015;34:589-596.

43 Ciszewicz M, Polubinska A, Antoniewicz A, Suminska-Jasinska K, Breborowicz A: Sulodexide suppresses inflammation in human endothelial cells and prevents glucose cytotoxicity. Trans Res 2009;153:118-123.

44 Gabryel B, Jarzabek K, Machnik G, Adamczyk J, Belowski D, Obuchowicz E, Urbanek T: Superoxide dismutase 1 and glutathione peroxidase 1 are involved in the protective effect of Sulodexide on vascular endothelial cells exposed to oxygen-glucose deprivation. Microvasc Res 2016;103:26-35. 


\section{Cellular Physiology Cell Physiol Biochem 2016;40:621-632 and Biochemistry \begin{tabular}{c|c} 
DOI: 10.1159/000452575 & P 2016 The Author(s). Published by S. Karger AG, Basel \\
muww.karger.com/cph
\end{tabular}

45 Cha JJ, Kang YS, Hyun YY, Han SY, Jee YH, Han KH, Han JY, Cha DR: Sulodexide improves renal function through reduction of vascular endothelial growth factor in type 2 diabetic rats. Life Sci 2013;92:11181124.

46 Chen B, Tang J, Lu Z, Wang N, Gao X, Wang F: Primary Cutaneous Nocardiosis in a Patient with Nephrotic Syndrome: A Case Report and Review of the Literature. Medicine (Baltimore) 2016;95:e2490.

47 Mehrotra P, Patel JB, Ivancic CM, Collett JA, Basile DP: Th-17 cell activation in response to high salt following acute kidney injury is associated with progressive fibrosis and attenuated by AT-1R antagonism. Kidney Int 2015;88:776-784.

48 Lu Z, Yin J, Bao H, Jiao Q, Wu H, Wu R, Xue Q, Wang N, Zhang Z, Wang F: Coexistence of Acute Crescent Glomerulonephritis and IgG4-Related Kidney Disease. Case Rep Nephrol Dial 2016;6:89-95.

49 Wang F, Zhang G, Xing T, Lu Z, Li J, Peng C, Liu G, Wang N: Renalase contributes to the renal protection of delayed ischemic preconditioning via the regulation of hypoxia-inducible factor- $1 \alpha$. J Cell Mol Med 2015;19:1400-1409.

50 Wang F, Li J, Huang B, Zhao Q, Yu G, Xuan C, Wei M, Wang N: Clinical survey on contrast-induced nephropathy after coronary angiography. Ren Fail. 2013;35:1255-1259.

51 Altunoren O, Balli M, Eren N, Tasolar H, Arpaci A, Caglayan CE, Yavuz YC, Gungor O: Is Nebivolol Really Effective in Preventing Contrast Induced Nephropathy? Kidney Blood Press Res. 2015;40:533-541. 